\title{
Conjuntivite bacteriana secundária à doença dentária em chinchilas (Chinchilla lanigera)
}

\author{
Bacterial conjunctivitis secondary to dental disease in chinchillas (Chinchilla lanigera)
}

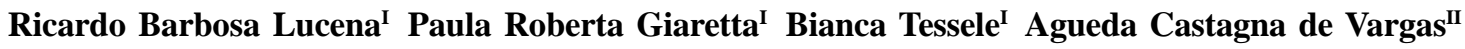 \\ Claudio Severo Lombardo Barros ${ }^{\mathrm{I}^{*}}$
}

\begin{abstract}
São relatados três casos de conjuntivite bacteriana RESUMO associada à doença dentária grave em chinchilas. Todas as chinchilas afetadas tinham histórico de emagrecimento, hipersalivação e epífora, que progrediu para exsudação ocular purulenta. Durante a necropsia, foi constatado marcado alongamento da coroa clínica dos incisivos e molares, e crescimento do ápice dentário, causando deformação óssea e compressão do canal lacrimal. Histologicamente, observouse infiltrado de neutrófilos na conjuntiva e pálpebras. Cultivo microbiológico do exsudato ocular revelou crescimento de Staphylococcus coagulase-positiva . Uma compressão do canal lacrimal pelo crescimento dentário excessivo impediu a drenagem das lágrimas, resultando em epífora. Esse é um importante fator predisponente para infecção bacteriana ocular em chinchilas.
\end{abstract}

Palavras-chave: má oclusão, dente, roedores, obstrução nasolacrimal, patologia.

\section{ABSTRACT}

Three cases of bacterial conjunctivitis associated with severe dental disease in chinchillas are described. All affected chinchillas had a history of weight loss, ptyalism, and epiphora which progressed to suppurative ocular exsudation. At necropsy incisor and molar teeth revealed marked elongation of the clinical crown and overgrowth of the dental apexes resulting in deformation of the tear ducts. Histologically, there was neutrophilic infiltrate in the conjunctiva and eyelid skin. Microbiological culture carried out in samples from the ocular exsudate yielded Staphylococcus coagulase-positive. Compression of the lacrimal duct by dental overgrowth compromised tear draining and resulting in epiphora. This is a major predisposing factor inducing bacterial ocular infection in chinchillas.
Key words: malocclusion, tooth, rodents, nasolacrimal, pathology.

Má oclusão dentária é descrita como um dos principais problemas de saúde em roedores domésticos (CAPELLO, 2008). Esse problema é grave, especialmente em chinchilas, e resulta num complexo de sinais clínicos tanto primários relacionados à função dentária, quanto secundários, por interferir com outros órgãos e sistemas (CROSSLEY, 2001). Chinchilas acometidas por má oclusão dentária podem desenvolver timpanismo, constipação, anorexia e inanição, hipersalivação, perda dos pelos da região perioral, deformação do maxilar, obstrução do canal lacrimal, que resulta em epífora, abscedação retrobulbar e exoftalmia (CROSSLEY, 2001; DONNELLY,2004).

Diferentes estudos têm demonstrado lesões secundárias à doença dentária em chinchilas (CROSSLEY,2001; DERBAUDRENGHIEN et al., 2010). No entanto, não são encontrados relatos de casos associados à conjuntivite purulenta com isolamento bacteriano. O presente trabalho tem o objetivo de descrever a ocorrência de conjuntivite bacteriana secundária à má oclusão dentária em três chinchilas.

Foram identificadas três chinchilas com conjuntivite associada à má oclusão dentária num estudo envolvendo 252 necropsias de chinchilas, realizadas no Laboratório de Patologia Veterinária da

'Departamento de Patologia, Laboratório de Patologia Veterinária, Universidade Federal de Santa Maria (UFSM), Av. Roraima, 1000, Camobi, 97105-900, Santa Maria, RS, Brasil. E-mail: claudioslbarros@uol.com.br. *Autor para correspondência.

IIDepartamento de Medicina Veterinária Preventiva, Laboratório de Bacteriologia, UFSM, Santa Maria, RS, Brasil. 
Universidade Federal de Santa Maria (LPV-UFSM) entre os anos de 1997-2011 (LUCENA et al., 2012). As chinchilas 1 (fêmea de 5 anos) e 2 (fêmea de 8 anos) pertenciam à propriedade $\mathrm{A}$, localizada em Santa Maria, RS. A chinchila 3 (macho de 2 anos) pertencia à propriedade B, localizada em Nova Palma, RS. As chinchilas foram remetidas em diferentes datas (maio, julho e agosto de 2010).

Todas as chinchilas tinham histórico de diminuição da ingestão de ração, emagrecimento progressivo, hipersalivação, epífora, com posterior exsudação ocular purulenta, sensibilidade à luz e formação de crostas perioculares. Adicionalmente, a chinchila 3 demonstrou aumento de volume abdominal e, à palpação, foram observadas massas firmes no intestino (constipação). A evolução desde os primeiros sinais clínicos até a morte variou de 3 semanas a 2 meses. Todas as chinchilas eram alimentadas com ração comercial peletizada. Foi realizado exame radiográfico na chinchila 2. Na radiografia, foi observada acentuada irregularidade oclusal, com formação de espículas dentárias mesial e distal, e marcado alongamento dos dentes incisivos.

Durante a necropsia, foi constatado caquexia em todas as chinchilas. Havia alopecia na pele periocular e perioral. Observavam-se crostas aderidas às pálpebras e grande quantidade de exsudado ocular mucopurulento (bilateral em duas chinchilas e apenas unilateral na terceira chinchila). A conjuntiva estava marcadamente vermelha e recoberta por exsudado seroso e mucopurulento (Figura 1).

Os dentes incisivos de todas as chinchilas estavam marcadamente alongados (Figura 1). O crescimento excessivo dos dentes resultou em alteração do perfil da cabeça. A profundidade da mandíbula estava aumentada nas três chinchilas, devido ao crescimento de osso na crista alveolar e distorção do córtex ventrolateral, secundário ao crescimento apical. A pré-maxila e a parte rostral da maxila estavam significativamente mais curtas que o normal. Os ápices dos dentes incisivos superiores penetraram a maxila, enquanto as coroas clínicas apresentavam crescimento para dentro da boca. A invasão da bula alveolar pelo ápice dos dentes molares resultou em obstrução do canal nasolacrimal em todas as chinchilas. Ulceração bilateral da mucosa oral devido ao trauma causado por espículas dentárias foi um achado comum.

Fragmentos de pele (pálpebra), encéfalo, pulmão, coração, rins, fígado, estômago, intestinos, baço, linfonodos, pâncreas, adrenais e os olhos foram fixados em formol tamponado a $10 \%$, embebidos em parafina, seccionados a $3 \mu \mathrm{m}$ e corados com hematoxilina e eosina (HE). Secreção ocular e fragmentos das pálpebras e conjuntivas foram remetidos para cultura bacteriológica.

Histologicamente, nas pálpebras e conjuntiva, observou-se moderado infiltrado inflamatório, constituído principalmente por neutrófilos, íntegros e degenerados, e poucos linfócitos, plasmócitos e macrófagos. Nos demais órgãos avaliados, não foram observadas alterações microscópicas. A cultura microbiológica da secreção ocular das três chinchilas resultou em crescimento de Staphylococcus coagulase-positiva.

As mortes das chinchilas do presente relato decorreram da falha na ingestão de alimentos,

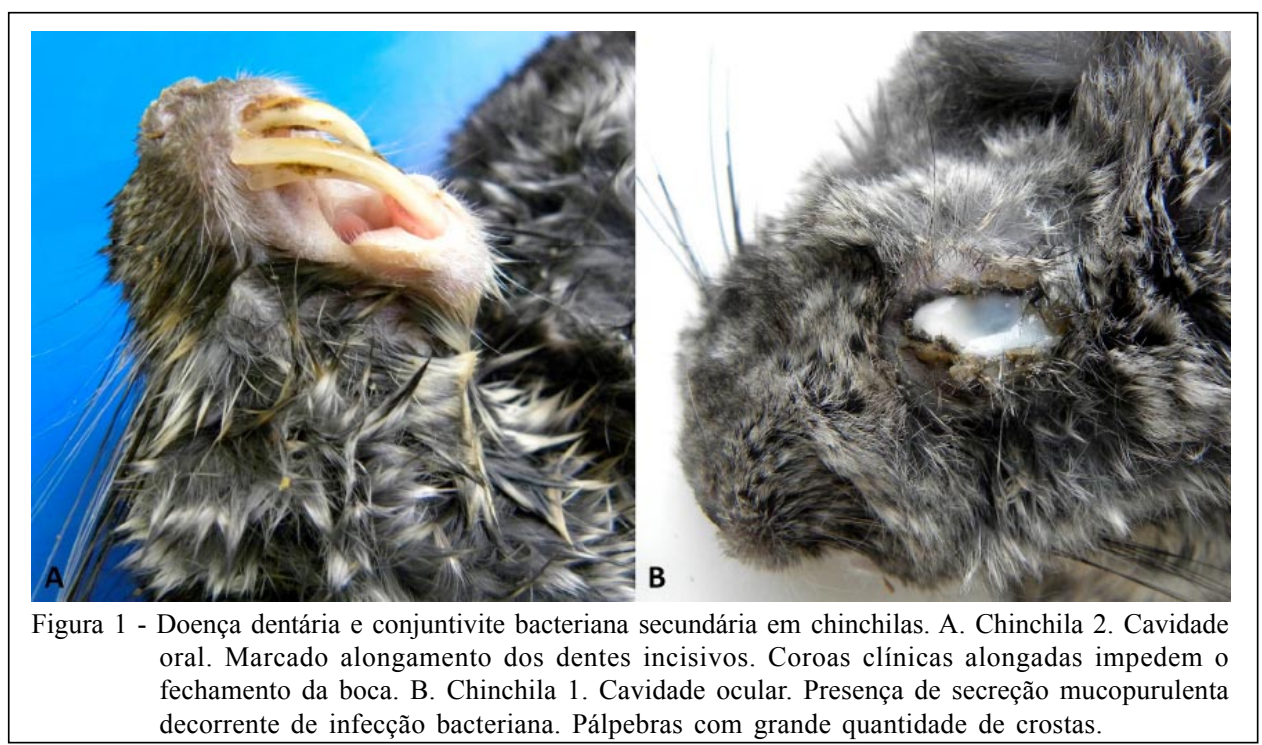

Ciência Rural, v.42, n.11, nov, 2012. 
complicada pela infecção ocular secundária ao problema dentário. Doença dentária é uma importante causa de morte em chinchilas, devido às complicações diretas causadas pela incapacidade de ingestão dos alimentos ou por complicações secundárias (CROSSLEY, 2001; CAPELLO, 2008). Nas chinchilas acometidas por má oclusão, a mastigação se torna muito dolorosa ou impossível, anorexia aparece progressivamente, com posterior perda de peso, observada em $79 \%$ dos animais (DONNELLY, 2004). Uma vez que as chinchilas reduzem a ingestão de fibras, ou, pior, deixam de comer, o sistema digestório não consegue funcionar adequadamente (DONNELLY, 2004). Excrementos fecais geralmente tornam-se menores e secos, consequentemente, timpanismo ou constipação pode ocorrer, como observado em uma das chinchilas. Desconforto oral ou dor resultam em movimentos restritos da mandíbula, que, por sua vez, culmina em salivação excessiva (CROSSLEY \& ROXBURGH, 1999; CROSSLEY, 2001). Alongamento da coroa de reserva dos maxilares pode causar deformação e até mesmo obstrução do canal lacrimal ósseo (CROSSLEY \& ROXBURGH, 1999). As lágrimas não são evacuadas, o que resulta em epífora e alteração dos pelos periorbitários (CROSSLEY, 2001). Além disso, é possível desenvolver doença ocular secundária, como observado nas chinchilas deste estudo, que desenvolveram conjuntivite purulenta devido à contaminação bacteriana secundária.

Em outras espécies animais, como cães e gatos, manifestações oculares de doença dentária incluem sinais orbitários, periorbitários, conjuntivais, nasolacrimais, neuro-oftalmológicos, e até mesmo sinais uveias (RAMSEY et al., 1996). Em coelhos, o bloqueio do canal lacrimal é uma das consequências mais comuns da doença dentária; essa alteração é denominada dacriocistite (COOPER, 2011). Nas chinchilas do presente relato, apesar da obstrução do canal lacrimal, não foi observada dilatação do saco lacrimal por lágrimas ou conteúdo purulento, como descrito nos coelhos com dacriocistite. Um estudo de 56 chinchilas acometidas por doença dentária no Reino Unido revelou ocorrência de corrimento ocular em 11 destas (20\%), uma consequência do comprometimento do canal lacrimal (CROSSLEY, 2001). As chinchilas do presente relato fazem parte de um estudo retrospectivo e prospectivo de necropsia de 252 chinchilas entre 1997 2011 (LUCENA et al., 2012). Foi constatado que, durante esse período, 18 chinchilas morreram em decorrência de doença dentária (7\%). Dentre essas, três desenvolveram conjuntivite bacteriana por Staphylococcus coagulase-positiva (16\% das chinchilas com doença dentária e 1\% de todas as chinchilas necropsiadas). Estes achados comprovam que doença dentária é uma importante síndrome em chinchilas e que complicações, como a obstrução do canal lacrimal, induzem grande desconforto e perda da condição corporal nas chinchilas acometidas por crescimento dentário excessivo.

A observação de conjuntivite bacteriana secundária à doença dentária em chinchilas parece ser relativamente frequente. Estudos com maior número de chinchilas acometidas por doença dentária deverão ser realizados para se determinar a prevalência de conjuntivite associada à má oclusão dentária nesta espécie.

\section{REFERÊNCIAS}

CAPELLO, V. Diagnosis and treatment of dental disease in pet rodents. Journal of Exotic Pet Medicine, v.17, n.2, p.114123, 2008. Disponível em: <http://www.sciencedirect.com/ science/article/pii/S1557506308000256>. Acesso em: 10 jan. 2012. doi: $10.1053 / \mathrm{j}$.jepm.2008.03.010.

COOPER, S. Dacryocystitis in rabbits. Companion Animal, v.16, n.2, p.19-21, 2011. Disponível em: <http://onlinelibrary.wiley.com/ doi/10.1111/j.2044-3862.2010.00015.x/pdf>. Acesso em: 10 jan. 2012. doi: $10.1111 / \mathrm{j} .2044-3862.2010 .00015 . \mathrm{x}$.

CROSSLEY, D.A. Dental disease in chinchillas in the UK. Journal Small Animal Practice, v.42, n.1, p.12-19, 2001. Disponível em: <http://onlinelibrary.wiley.com/doi/10.1111/ j.1748 5827.2001.tb01977.x/pdf>. Acesso em: 10 jan. 2012. doi: $10.1111 / \mathrm{j} .17485827 .2001 . t b 01977 . x$.

CROSSLEY, D.A.; ROXBURGH, G. The site of obstruction of the lacrimal drainage system in chinchillas (Chinchilla lanigera) with "wet eye". In: BRITISH SMALL ANIMAL VETERINARY ASSOCIATION CONGRESS, 1999, Birmingham, West Midlands (UK). Proceedings... Birmingham: BSAVA, 1999. p.21-22.

DERBAUDRENGHIEN, A. et al. Dental pathology in chinchillas. Vlaams Diergeneeskundig Tijdschrift, v.79, n.5, p.345-358, 2010. Disponível em: <http://vdt.ugent.be/ showabstract.php?id=651>. Acesso em: 15 dez. 2011.

DONNELLY, T.M. Disease problems of chinchillas. In: QUESENBERRY, K.E.; CARPENTER, J.W. Ferrets, rabbits and rodents: clinical medicine and surgery. St. Louis: Saunders, 2004. p.255-266.

LUCENA, R.B et al. Doenças de chinchilas (Chinchilla lanigera). Pesquisa Veterinária Brasileira, v.32, n.6, p.529-535, 2012.

RAMSEY, D.T. et al. Ophthalmic manifestations and complications of dental disease in dogs and cats. Journal of the American Animal Hospital Association. v.32, p.215224, 1996. 